\title{
Structure of AIN films deposited by magnetron sputtering method
}

\author{
K. Nowakowska-LangieR ${ }^{1 *}$, R. Chodun ${ }^{2}$, K. ZduneK $^{2}$, R. Minikayev $^{3}$, R. Nietubyc $^{1}$ \\ ${ }^{1}$ Department of Material Physics, National Centre for Nuclear Research (NCBJ), Andrzeja Soltana 7, \\ 05-400 Otwock-Swierk, Poland \\ ${ }^{2}$ Faculty of Materials Science and Engineering, Warsaw University of Technology, Woloska 141, 02-507 Warsaw, Poland \\ ${ }^{3}$ Institute of Physics, Polish Academy of Sciences, al. Lotnikow 32/46, 02-668, Warsaw, Poland
}

AlN films on a Si substrate were synthesized by magnetron sputtering method. A dual magnetron system operating in AC mode was used in the experiment. Processes of synthesis were carried out in the atmosphere of a mixture of Ar/ $\mathrm{N}_{2}$. Morphology and phase structure of the AlN films were investigated at different pressures. Structural characterizations were performed by means of SEM and X-ray diffraction methods. Our results show that the use of magnetron sputtering method in a dual magnetron sputtering system is an effective way to produce AlN layers which are characterized by a good adhesion to the silicon substrate. The morphology of the films is strongly dependent on the $\mathrm{Ar} / \mathrm{N}_{2}$ gas mixture pressure. An increase of the mixture pressure is accompanied by a columnar growth of the layers. The films obtained at the pressure below $1 \mathrm{~Pa}$ are characterized by finer and compacter structure. The AlN films are characterized by a polycrystalline hexagonal (wurtzite) structure in which the crystallographic orientation depends on the gas mixture pressure.

Keywords: AlN films; magnetron sputtering method; crystalline structure

(C) Wroclaw University of Technology.

\section{Introduction}

Aluminum nitride is a material with a broad range of applications due to numerous physical and chemical properties. The properties of aluminum nitride (AlN) thin films deposited using plasma enhanced techniques have been studied for over twenty years. It was shown that AlN thin films show a number of highly demanded properties, i.e. high thermal conductivity and stability, chemical inertness or high hardness. Moreover, the films exhibit excellent electrical and optical properties, i.e. high breakdown voltage and wide band-gap or low extinction coefficient in a wide spectral range, and a high refractive index [1-5]. All the properties allow us to treat the films as prospective material for mechanical, chemical and electrical applications.

In case of AlN layers synthesis a predominant texture growth is observed. The piezoelectric properties of highly oriented films (along the c-axis) are

*E-mail: k.nowakowska-langier@ncbj.gov.pl similar to those of a single-crystal. If highly c-axisoriented AlN films are grown, a high electromechanical coupling coefficient and low losses can be achieved, therefore, the material with such texture is economically advantageous. The highly c-axisoriented AlN is an attractive material for small to medium bandwidth filters $[6,7]$ as a part of integrated ULSI devices, optical sensors in the UV range or in acousto-optic devices [1-5].

Taking into account potential applications of AlN layers, in which the preferred 00001 structure is expected, the optimization of their growth has been widely discussed. AlN thin films can be synthesized using several techniques, such as reactive magnetron sputtering $[8,9]$, molecular beam epitaxy [10, 11], laser ablation [12, 13], or pulse laser deposition (PLD) [14]. A usual reactive sputtering is generally known as an effective method for preparing highly oriented AlN thin films [15-17], however, clear, optimal parameters that can resolve the problem have not been obtained yet. Many parameters of the sputtering processes significantly 
affect the orientation of the AlN layers. As reported

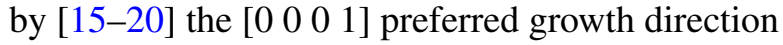
is dependent on many parameters, e.g. the change of $\mathrm{N}_{2}$ concentration and/or $\mathrm{Ar} / \mathrm{N}_{2}$ mixture pressure $[15,16,18,19]$, the type of substrate [18], the thickness of interlayer [20].

The aim of our study was to examine the morphology of the structure of aluminum nitride layers depending on the pressure during the deposition process carried out in a dual magnetron system, working in AC mode. In addition, we tried to define deposition conditions that would be advantageous for obtaining AlN films showing promising properties from a point of view of certain applications.

\section{Experimental}

\subsection{Films deposition}

A dual magnetron sputtering system with two WKM-100 circular magnetrons was used in this experiment. Schematic view of the apparatus is shown in Fig. 1.

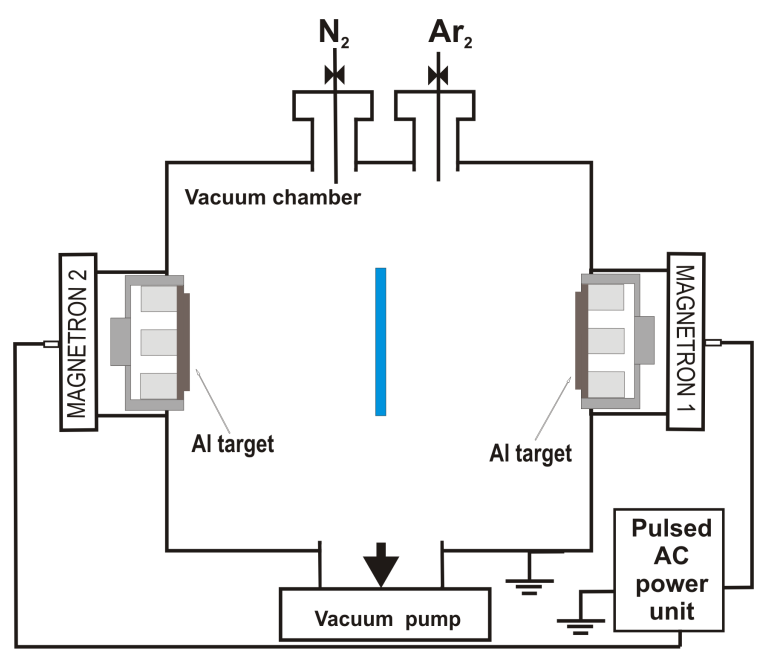

Fig. 1. Schematic view of the magnetron sputtering system used in our experiment.

The magnetrons were placed opposite to each other at a distance of $350 \mathrm{~mm}$. Targets of 100 $\mathrm{mm}$ of diameter and $8 \mathrm{~mm}$ of thickness were made of aluminum (1050A). The magnetrons were supplied by a $10 \mathrm{~kW}$ pulse power supplier, from
DORA PS, operating in AC mode with a frequency of $80 \mathrm{kHz}$ and modulation of about $1 \mathrm{kHz}$ [21]. A grounded substrate stage was placed perpendicular to the magnetron axis. The AlN films were deposited on silicon substrates that were not additionally heated during any stage of the deposition process. The substrates were not rotated during the synthesis. The vacuum chamber was pumped with diffusion and rotary pumps. This system yielded a base pressure in the sputtering chamber better than $3 \times 10^{-4} \mathrm{~Pa}$. Argon with $99.999 \%$ purity was used as a sputtering gas. Nitrogen $(99.999 \%)$ was used as a reactive gas. Metering needles were used to distribute gases into the vacuum chambers. In our experiments we used a wide range of pressures, from a relatively low to a relatively high, (generally not used in the synthesis of AlN layers). It means that the reactive process of AlN layers growth took place in presence of $\mathrm{Ar} / \mathrm{N}_{2}$ gas mixture, where a pressure was from 0.1 to $15 \mathrm{~Pa}$. All the synthesis processes were conducted in a transient mode of the deposition process under the conditions of gas mixture pressure established on the basis of the relation of the effective power to the circulating power [21]. Target current was $5 \mathrm{~A}$ and deposition time was 180 minutes.

\subsection{Characterization of the films}

The morphology of the AlN films was investigated using scanning electron microscope (JEOL Leo 1530). The X-ray diffraction measurements were performed using monochromatic synchrotron radiation $(\lambda=1.54056 \AA)$ at the $\mathrm{W} 1.1$ beamline (equipped with a $6+2$-circle diffractometer) at DESY-Hasylab. Diffraction patterns were collected in two scanning modes: $2 \theta-\omega$ symmetrical scan and coplanar $2 \theta$ scan in the glancing geometry with $\omega$ angle fixed at $1^{\circ}$.

In the symmetrical $2 \theta-\omega$ scan mode, the crystallographic orientation of Si substrate was directed parallel to the incident beam. This type of measurement geometry permits to collect the signal, mostly from film crystallites which are co-oriented to the crystallographic orientation of the substrate. The glancing geometry allowed us to obtain a strong diffracted signal from the possible polycrystalline 
fraction of thin film, with a negligible or low signal from the substrate and low background scattering effect. Thin film lattice parameters were determined by the whole-pattern decomposition procedure (Le Bail method) [22] with the help of Fullprof.2k (v. 2.70) program [23]. The pseudo-Voigt profile shape function was assumed. Generally, two groups of parameters were refined: lattice parameters with systematic line-shifts and peak shape parameters (total 6 parameters refined). The background points were set manually.

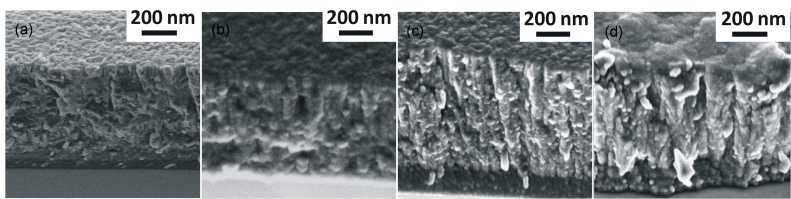

Fig. 2. SEM pictures of cross-section view of the AlN layers deposited at (a) $0.1 \mathrm{~Pa}$, (b) $1 \mathrm{~Pa}$, (c) $5 \mathrm{~Pa}$, and (d) $10 \mathrm{~Pa}$ of the $\mathrm{Ar} / \mathrm{N}_{2}$ gas mixture pressure.

\section{Results and discussion}

Fig. 2 shows the morphology of the aluminum nitride films obtained by the magnetron sputtering. It illustrates the relationship between the size of the columnar structure of the films and the pressure of the $\mathrm{Ar} / \mathrm{N}_{2}$ gas mixture. As one can see, the growing pressure influences the obtained film morphology. The increasing of the gas mixture pressure is accompanied by a tendency to columnar growth. The columnar structure is clearly visible in the AlN film synthesized at 5 and 10 Pa pressure (Fig. 2c and 2d), while the films obtained at the pressure below $1 \mathrm{~Pa}$ are characterized by finer and compacter structure. The obtained result is significant from the point of view of columnar crystallites growth, characteristic of magnetron sputtering method. It is known that at low substrate temperature during magnetron sputtering the layers most typically show a columnar crystallographic structure. The size of the crystallites depends on pressure and at lower pressure the films exhibit finer structure. This can be explained by the theory of phase formation and crystal growth according to the Thornton model [24].

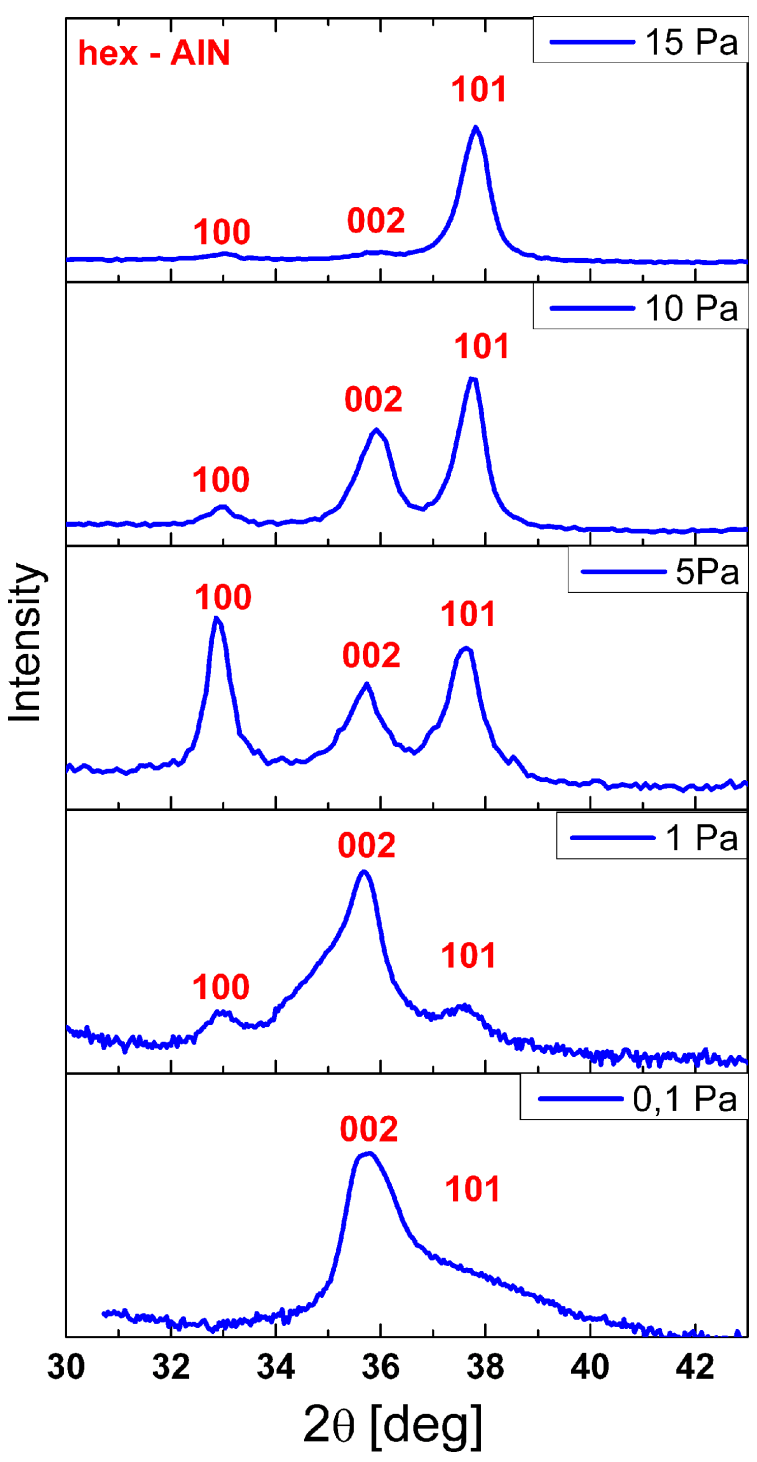

Fig. 3. X-ray diffraction patterns measured for the AlN layers obtained at different $\mathrm{Ar} / \mathrm{N}_{2}$ gas mixture pressures.

X-ray phase analysis (Fig. 3) confirms the presence of polycrystalline, hexagonal wurtzite structure in the studied aluminum nitride films that do not include any impurity phases. The investigated AlN thin films are characterized by different preferred growth directions that depend on the $\mathrm{Ar} / \mathrm{N}_{2}$ gas mixture pressure. An increase in the pressure leads to the formation of structures that are mainly formed by the crystallites oriented along the [ $\left[\begin{array}{lll}1 & 0 & 1\end{array}\right]$ direction, while at low pressure $(0.1 \mathrm{~Pa}$ and $1 \mathrm{~Pa}$ ) the prevalent orientation of the growth is 
(lo $\left.\begin{array}{lll}0 & 1\end{array}\right)$ (along c-axis). Due to potential electronic applications, the AlN thin films with column-like structures are unwanted, therefore, more detailed studies were carried out for the films obtained at low pressures. For detailed structural studies and phase purity improvement, the diffraction patterns of the AlN films obtained at $0.1 \mathrm{~Pa}$ and $1 \mathrm{~Pa} \mathrm{Ar} / \mathrm{N}_{2}$ gas mixture pressure were collected in glancing geometry (Fig. 4). Applying of whole-pattern decomposition method allowed us to determine lattice parameters of the thin films. The obtained results are collected in Table 1. The lattice parameter values match well with those previously reported in literature [25, 26]. The AlN layers synthesized at low mixture pressure show a promising morphology and phase composition for the application in electronic devices.

Table 1. The values of lattice parameters and grain size of the hexagonal AlN films deposited at different $\mathrm{Ar} / \mathrm{N}_{2}$ mixture pressures.

\begin{tabular}{cccc}
\hline \multirow{2}{*}{ Sample } & \multicolumn{2}{c}{ Lattice constant } & \multirow{2}{*}{ References } \\
\cline { 2 - 3 } & $\mathrm{a}[\AA]]$ & $\mathrm{c}[\AA]$ & \\
\hline \hline AlN 0.1Pa & $3.113(3)$ & $5.02(2)$ & This work \\
AlN 1Pa & $3.116(7)$ & $5.00(2)$ & This work \\
Powder & 3.112 & 4.982 & {$[25]$} \\
& $3.11197(2)$ & $4.98089(4)$ & {$[26]$} \\
\hline
\end{tabular}

\section{Conclusions}

The results show that the application of magnetron sputtering in a dual magnetron system allows an effective deposition of the AlN films on non intentionally heated substrates. The AlN films are characterized by polycrystalline, hexagonal wurtzite structure. The morphology and predominant texture growth of the hexagonal AlN structure depends on the $\mathrm{Ar} / \mathrm{N}_{2}$ gas mixture pressure. The results show that the most promising morphology and phase composition have the films deposited in $\mathrm{Ar} / \mathrm{N}_{2}$ pressure range from 0.1 to $1 \mathrm{~Pa}$. An increase of pressure is accompanied by a columnar growth of the layers. The films obtained at a pressure below $1 \mathrm{~Pa}$ are characterized by finer and compacter structure.

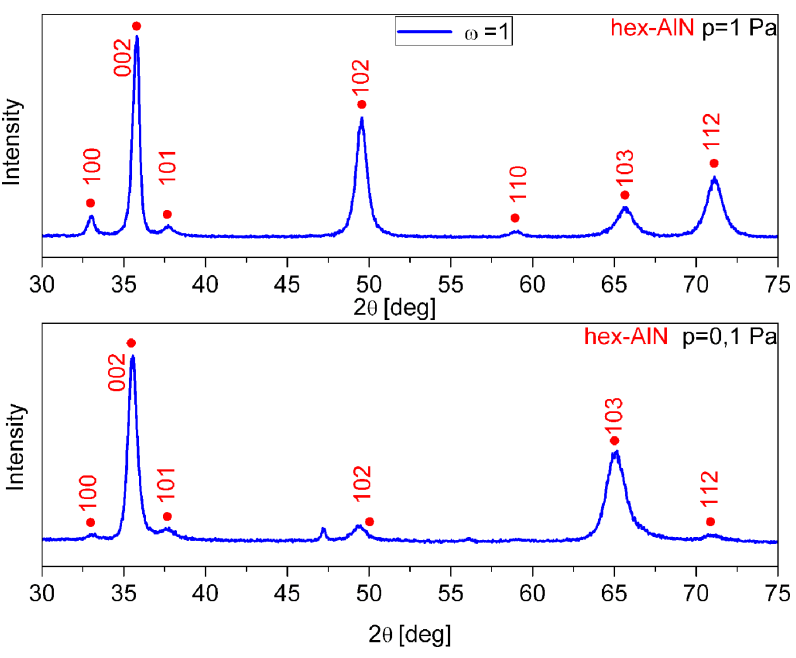

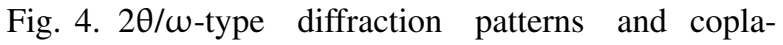
nar $2 \theta$-type scan in glancing incidence geometry measured for the AlN films obtained at different $\mathrm{Ar} / \mathrm{N}_{2}$ gas mixture pressures: $0.1 \mathrm{~Pa}$ (left), $1 \mathrm{~Pa}$ (right). The peaks of highest intensity in the patterns are related to $\left(\begin{array}{lll}0 & 0 & 1\end{array}\right)$-oriented bulk AlN.

\section{References}

[1] Kar J.P., Bose G., Tuli S., Vacuum, 81 (4) (2006), 494.

[2] Chiu K.H., Chen J.H., Chen H.R., Huang R.S., Thin Solid Films, 515 (2007), 4819.

[3] Olivares J., Rivera J., Briones A., Diam. Relat. Mater., 16 (2007), 1421.

[4] Jang K., LeE K., Kim J., Hwang S., LeE J., DhunGel S.K., Jung S., Yi J., Mat. Sci. Semicon. Proc., 9 (2006), 1137.

[5] Prinz G.M., Ladenburger A., Feneberg M., SChirra M., Thapa S.B., BiCKermann M., EPElBAum B.M., Scholz F., Thonke K., SAuer R., Superlattice. Microst., 40 (2006), 513.

[6] Dubois M.A., Muralt P., Appl. Phys. Lett., 74 (1999), 3032.

[7] Loebl H.P., Klee M., Metzmacher C., Brand W., Milsom R., LoK P., Mater. Chem. Phys., 79 (2003), 143.

[8] DimitrovaV., Manova D., Paskova T., Uzunov T., IVANov N., DecheV D., Vacuum, 51 (1998), 161.

[9] Manova D., Dimitrova V., FuKareK W., KarpuzOV D., Surf. Coat. Tech., 106 (1998), 205.

[10] Stevens K.S., Ohtani A., Kinniburgh M., Beresford R., Appl. Phys. Lett., 65 (1994), 321.

[11] Yoshida S., Misawa S., FujiI Y., TAKada S., Hatakawa H., Gonda S., ITOH A., J. Vac. Sci. Technol., 16 (1979), 990.

[12] ОKамоTO M., YAMAOKA M., YAP Y.K., Yoshimura M., Mori Y., SAsaki T., Diam. Relat. Mater., 9 (2000), 516. 
[13] Norton M.G., Kotula P.G., Carter C.B., J. Appl. Phys., 70 (1991), 2671.

[14] Vispute R., Thin Solid Films, 299 (1997), 94.

[15] OKano H., Takahashi Y., Tanaka T., Shibata K., NaKano S., Jpn. J. Appl. Phys., 31 (1992), 3446.

[16] Cheng C.C., Chen Y.C., Wang H.J., Chen W.R., J. Vac. Sci. Technol. A, 14 (1996), 2238.

[17] NAik R.S., Reif R., Lutsky J.J., Sodini C.G., J. Electrochem. Soc., 146 (1999), 691.

[18] Ohuchi S., Russel P.E., J. Vac. Sci. Technol. A, 5 (1987), 1630.

[19] Hwang B.-H., Chen C.-S., Lu H.-Y., Hsu T.-C., Mat. Sci. Eng. A-Struct., 325 (2002), 380.

[20] Kamohara T., Akiyama M., Ueno N., NonAKA K., Tateyama H., J. Cryst. Growth, 275 (2005), 383.

[21] Posadowski W., Wiatrowski A., Dora J., RADZIŃSKI Z., Thin Solid Films, 516 (14) (2008), 4478.
[22] Bail Le A., Duroy H., Fourquet J.L., Mat. Res. Bull., 23, (1988), 447.

[23] Rodriguez-Carvajal J., Comm. Powder Diffr. Newsl., 26 (2001), 12.

[24] Thornton J.A., J. Vac. Sci. Technol., 4 (1974), 666.

[25] Goldberg Y., Aluminum Nitride (AlN), in: LeVINSHTEIN M.E., Rumyantsev S.L., SHUR M.S. (Eds.), Properties of Advanced Semiconductor Materials GaN, $A l N$, InN, BN, SiC, SiGe, John Wiley \& Sons, Inc., New York, 2001.

[26] Paszkowicz W., Podsiadlo S., Minikayev R., J. Alloy. Compd., 382 (2004), 100.
Received 2015-01-15

Accepted 2015-04-25 